Drawing from teaching and administrative experiences, this chapter outlines mentoring opportunities to help students succeed in their undergraduate years and prepare for life in an increasingly diverse society.

\title{
Promoting Understanding of Diversity Through Mentoring Undergraduate Students
}

\author{
Margaret Scisney-Matlock, John Matlock
}

During the past decade, higher education institutions throughout the United States have placed considerable emphasis on increasing their numbers of minority and underrepresented students, improving racial climates on campuses, and addressing retention and graduation issues which generally tend to be lower for these students than for majority students. At the same time, colleges and universities have made significant efforts to demonstrate that diversity learning and teaching benefits all students who are being prepared for an increasingly diverse world and workplace. As institutions seek to deal with these multiple, and often complex, challenges, many faculty have had to examine their assumptions and roles relative to a multicultural campus and how they interact with students of color, as well as communicate the importance of diversity to all their students.

Furthermore, there is heightened interest in the role of mentoring within institutions of higher education as related to enhancing multicultural awareness in all students. Numerous essays, articles, and research studies have offered broad interpretations on the importance of relationships between faculty and students who come from diverse communities throughout the world. Most seem to conclude that for students to benefit from mentoring that can result in greater retention and graduation rates, as well as enhanced satisfaction with their campus experiences, the interactions between the faculty and students must be comprehensive and yet specific enough to address the social, academic, and personal development needs of students (Astin, 1993; Pascarella, Terenzini, and Hibel, 1978; Tinto, 1993). 
These authors stress the importance of faculty involvement in the overall success of students in general and in most cases authors allude also to the impact on underrepresented students.

This chapter will explore some of the issues and challenges connected with mentoring students of color and the significant role that faculty have in working with this growing population-both inside and outside of the classroom-in promoting diversity learning and teaching. It will offer suggestions on how faculty can examine and challenge their own assumptions regarding perceptions of diversity and the impact they have on all students, especially students of color. Finally, practical strategies will be offered that faculty can use to encourage mentees to "think out of the box" regarding diversity. In this way, issues of diversity can often be addressed through effective faculty mentoring of students. Student comments used throughout the chapter are from undergraduates who participated in a comprehensive and longitudinal study on the impact of campus diversity during their four years in college (University of Michigan, 1999).

\section{Defining Mentoring and Diversity Concepts as a Faculty Member}

As discussed in many chapters of this book, effective mentoring can have a powerful impact on students during the time that they are in college and also when they enter graduate or professional school, or the workforce. Often, students' overall success will be influenced significantly by the impact of the mentoring relationships with faculty. Additionally, how students gain skills in interacting with others who are different in some way will be influenced by the messages given to them by faculty.

Depending on the institutional type, many undergraduates arrive on campus with very little understanding of students who might be significantly dissimilar based on racial and ethnic differences, as well as those with religious and geographic diversity (for example, international students). While they might have a willingness to establish relationships with various students, they do bring images or stereotypes of others that are not based on actual experiences or interactions. For example, a student might not have had any substantial interactions with minority students but has developed impressions based on the media, limited interactions, and what they have been told by parents and others in their communities.

This poses many challenges and barriers for undergraduates, particularly when we consider the large number who are young (eighteen- to nineteenyears old) and have limited life experience. For example, in a study conducted at a large higher-education institution, nearly 90 percent of entering white undergraduate students attended nearly all-white high schools and lived in all-white communities (University of Michigan, 1999). At the same time, nearly half of the African American students came from nearly all African American communities, and this was true of their high school as well. Stu- 
dents are often mixed together and expected to "work things out" relative to how they relate to each other. As one student commented, "diversity is pretty complicated stuff. When I arrived at my campus, they told us about the importance of diversity, but we didn't get the instructions to put it all together. I keep making a lot of mistakes relative to my interactions with others, and I don't know who to turn to for help." Often, it's the faculty who will have the most impact.

\section{Reaching Common Ground: Faculty Mentor Perspectives on Diversity May Differ from the Students'}

When the word "diversity" is used, it means different things to different faculty. Likewise, it also means different things to student mentees. It is important that one have a common understanding, not necessarily a common agreement, on what diversity means. For example, for a student of color, diversity may be perceived only in terms of race and ethnicity while someone else may see it from the perspective of race, gender, geography, sexual orientation, or religion. This is compounded by the fact that diversity or multiculturalism in the classroom generally is defined globally while it can be very specific when dealing with student populations. Therefore, a faculty member coming from a relatively homogeneous community may see the campus as very diverse while an African American or Latino student might perceive it to be not at all diverse. Or students may have preconceived views on the meaning of diversity. While this may seem unimportant, everyone tends to "play out his or her definition of diversity." In the end, considerable miscommunication can occur and ultimately damage good mentoring relationships on campus.

This understanding is important to developing good mentoring relationships because students often depend on faculty to help them work through these multiple definitions and maintain relationships with their peers who also are struggling with the transition to college. The goal is to work with all students in demonstrating that diversity is a value-added asset that uplifts all students, not only while they're on campus but throughout their life experience.

\section{Faculty as a Valuable Resource for Students of Color}

For students, faculty members represent a tremendous intellectual and experiential resource. Resourcefulness often has much to do with pointing students in the right direction and helping them find others who can facilitate their successful transition through their collegiate years. For students of color, who at times perceive the campus environment as hostile and unfriendly, barriers to their successful navigation of the system can hinder both academic performance and overall satisfaction with their experiences. 
As a result, there are times when students will need a variety of mentoring relationships with different individuals including those faculty who generally have the most contact with them. A major role of faculty mentors is to guide students in identifying campus resources that can help them, optimally before problems develop.

Mentors are most successful when they can direct students to individuals and campus offices that can address particular nonacademic needs that are best handled by others. For example, establishing individual contacts with staff in the financial aid office or counseling office will provide faculty with greater tools to help students and avoid situations in which students' concerns are not handled quickly. It is even more helpful when the faculty member has relationships with individuals in that unit so that when students are referred, there is a specific individual with whom to communicate.

Additionally, it is essential that students develop multiple and varied relationships. Academic success is only one dimension of overall student success and satisfaction. A student who is away from home may find comfort with an individual who is like a "parent away from home," and this individual may not be a faculty person at all. The key point for the mentoring faculty member is to recognize these multiple aspects of mentoring and not to erect barriers that could hinder a student's development. As one student lamented, "my mentor thinks that he owns me and gets very uptight when I mention that I talked to someone about a problem, even though I knew that he couldn't help me. He made me feel like I had offended him and now I'm very uncomfortable around him. I'm thinking about switching mentors."

\section{Expectations: Reaching Agreement}

Mentoring relationships often fail for students of color because expectations are not spelled out at the outset. It is valuable to ask students to write out what their expectations are for their mentors as a way of ascertaining that "we are all on the same page." Because mentoring can mean so many different things to different individuals, it is essential that some common understanding be reached.

Some students may appreciate a "check in" call or an e-mail message while others might view this as intrusive. A common mistake for faculty is to assume that "one size fits all" or that there is a single ideal process for mentoring all students and that all students subscribe to that definition. Agreements can be reached relative to number of contacts per semester and the degree of informality for meetings. Students can be quite evasive when they want only limited contact with a mentor or adviser who has been assigned to them, and students are often not sure what is expected of them or of their mentor. 


\section{Addressing Stereotypes That Can Affect Mentoring Relationships}

One significant barrier that hinders strong communication with students of color is the racial and ethnic stereotypes that faculty often bring to the relationship. Students of color are very sensitive to perceptions that there are low expectations set for them or that individuals have preconceived notions relative to their academic performance and their abilities to "fit" in the institutional culture.

One often hears from students of color who indicate that their mentors assume they are having problems with a particular course because they are not smart and just need to study harder. Other students have mentioned that their mentor asked about their urban experience even though the student may come from a suburban community. Other examples include assumptions that all students of color come from poor families and that they are first in their family to attend college. A Native American student reported that his faculty mentor automatically assumed that he came from a reservation when actually he had never visited one.

Likewise, Asian American students may feel that they are expected to do well in mathematics and sciences or that their mentor is surprised if they have an interest in majoring in social sciences, education, or English. Faculty mentors often overlook the fact that there is no monolithic minority group and that each student of color is indeed unique in his or her own way. Interestingly, many undergraduates of various ethnicities share these perceptions based on limited precollege interactions with students from other racial and ethnic backgrounds. Faculty members can do much to eliminate these stereotypes by examining their own assumptions and attitudes and those of the students that they mentor. Faculty must never exhibit biases and behaviors that either validate negative stereotypes, no matter how unintentional, or reinforce those that other students might harbor.

At times, it is essential that faculty mentors step outside their own space to interrelate with students on their "own turf." Organizations of students of color often are responsible for bringing various speakers to campus, but faculty are often noticeably not in attendance. A mentor should always look for opportunities to learn from students, which means taking advantage of interactions beyond the classroom and structured environments such as the faculty member's office.

Students of color often complain that students and faculty alike ignore the fact that there is tremendous variation within different racial and ethnic groups. For example, there are more than thirty ethnic groups included in the Asian American category. Likewise, Hispanic-Latino groups come from significantly different geographic areas of the Western Hemisphere. Because of the richness of diversity within and among various ethnic and racial groups, faculty must make every effort to ensure that stereotypes don't filter 
into their perceptions of students of color, which can present significant barriers in interactions with their mentees.

Finally, students bring multiple identities to campus and may often shift among them. A student of color who is female, for example, may place greater emphasis on gender issues than race or ethnicity and could be very resentful that her faculty mentor views everything from a racial perspective. As one student suggested, "my adviser is one dimensional. Because he has been to Africa, he thinks that he knows everything about African Americans. I have never been to Africa so I don't know what he's talking about. My first trip abroad will be to South America." It is essential to maintain an open mind, view each student as a unique individual and remember that the word "minority" has a broad definition that contains many, many groups. There is a richness of variation between and among the different racial and ethnic groups.

\section{Common Misconceptions Associated with Mentoring Students of Color}

Within the higher-education community, discussion often centers on whether faculty of color make the best mentors for students of color. Proponents of diversification of faculty often make this case while others suggest that any faculty member should be able to mentor a student of color. The appropriate match really depends on the situation and the motives of the various individuals. The most important factor is that students of color who have a faculty mentor perform better academically, regardless of the race or ethnicity of the faculty member. The body of research suggests that one significant characteristic of students who are not performing well academically is that they did not have a faculty mentor whom they perceived as essential to their development.

In effect, these students are navigating through the higher-educational system by themselves and have disengaged from the process of developing and refining relationships with faculty. Additionally, some nonmajority faculty use this as an excuse not to work with minority students by suggesting that they might be better served by having a matched race or ethnicity mentor. This poses several problems. Students are keenly aware when they are being put off or pushed away and have difficulty accepting this rationale. Furthermore, the notion erroneously assumes that it is the responsibility of faculty of color to mentor all students of color, which overlooks the fact that many predominantly white institutions have a paucity of minority faculty. It is the responsibility of all faculty to mentor all students, regardless of race or ethnicity. Finally, these feelings can easily cause a student to feel marginalized and invalidated at a critical time in their lives. One often hears students of color expressing the feeling that they don't belong at their institution, and they often cite their relationships with faculty. 


\section{Maintaining Trust in Mentoring Relationships}

Students of color, when discussing relationships with faculty who differ in race or ethnicity, often indicate that they had high expectations only to have some incident shatter their trust in the individual. For example, one student indicated that he checked with his adviser on a regular basis and thought that they had a good and satisfying relationship. However, after being told that he was doing well in his course work and that his progress was on target, he was called in to the minority affairs office only to be told that his adviser had indicated that he wasn't doing as well as he had expected. "I had never been so hurt in my life and never went to see that faculty member again. Now I'm suspicious of all faculty." It takes time to build trust relationships with students, which may be fragile at best. It only takes one incident for students to become distrustful and seek another mentor or, if they remain with their current one, to have minimal if any contact with that individual. Another student of color said that she had discovered her mentor was saying negative things about her. Before learning this, she had asked for several letters of recommendation, and was told by her adviser that she would be "more than happy to do one." Later the student found that the mentor was providing comments that had a negative impact on her in the job search. "If she had problems with me, I wish that she had told me instead of leading me to believe that all was well. I can never trust her again." These examples stress the need for mentors to be up-front with student-of-color mentees at all times, no matter how painful or difficult the discussion.

\section{Walking the Talk: Setting the Example in the Classroom}

Faculty need to know that students, especially students of color, are very aware of perceived inconsistencies that can interfere with mentoring relationships and can potentially erect walls of misunderstanding and miscommunication. For example, a student related that while his mentor is really nice and very helpful, he was concerned that in the classroom his mentor makes subtle disparaging remarks about women and minorities. "I'm not sure how to take this. If he truly was supportive of minorities, he would be more sensitive in the classroom." This student also added that during discussions about racial issues in the class, his mentor seemed to take sides with the white students. Another student commented about his mentor's research grants, stating that all the students who work with him are white. "I even indicated that I needed a job and he directed me to other offices when I knew that he was trying to fill several student positions." Another student suggested that his mentor treated students of color in the classroom as if they didn't exist, not recognizing them while they have their hands up but calling on them unexpectedly to respond to questions or asking them 
to give the minority point of view. These behaviors create tensions in the classroom. Mentors have to "walk the talk." Otherwise, students of color begin to doubt the sincerity of the mentor.

\section{Establishing Good Relationships with Student Affairs Units}

Much has been written about the differences in higher education between offices of academic affairs and student affairs. Often, the two key areas disagree philosophically about approaches to student development. While there have been improvements recently in drawing the two units together, much more needs to be done. The argument was made nearly a decade ago that the visible commitment to diversity seems largely to come from the office of student affairs with little involvement by the academic enterprise. Yet these are not mutually exclusive because student development issues certainly can have an impact on academic performance. For example, students who are having adjustment, financial aid, and housing problems will invariably experience difficulty academically and vice versa. Among African American, Latino or Hispanic, and Native American students, many come to their respective institutions with concerns about finances, and these concerns remain constant throughout the undergraduate years. Another illustration would be students of color who work longer hours than other students would, often while taking a full load at residential colleges. These students often have justifiable concerns about paying off tuition and related costs. Faculty mentors have to be cognizant of these issues and explore ways to get assistance for students. Academic problems may be rooted in other nonacademic issues. The mentor must have good contacts in other units of the campus including offices in student affairs that may have staff who specialize in resolving these problems.

\section{When the Mentor-Mentee Relationships Aren't Working}

When mentoring relationships just don't work well, there is a tendency to personalize situations between the mentor and mentee. It is important for all parties to try to determine the nature of the problem and how it can be resolved. Given the responsibilities of a faculty mentor, a greater involvement must be assumed by that individual. Efforts should be made to contact the student and have a frank discussion. However, it should not be a forced discussion. Students are often reluctant to discuss some issues with their mentor or with anyone else, including peers.

It may be necessary for faculty to facilitate their student's transition to another mentor, either in a formal or informal relationship. Perhaps the student has identified needs and the faculty knows some other individual more able to address them. For example, a student may want to have a mentor- 
ing relationship with someone whose academic field is connected with the student's goals. Additionally, it is wise, even when a student has ceased to be involved with a mentor, for the mentor to communicate via telephone or e-mail to see how the student is doing and to offer continuing assistance if needed. Climate perceptions are one of the major areas that appear to have an impact on the success of students of color, particularly in academic areas in relationships with faculty. Continued communication will often influence these perceptions to be positive.

\section{Role of Academic Administration in Mentoring and Diversity Activities}

Academic administrators including deans, department chairs, and academic support persons can play a significant role in ensuring that there is a supportive climate for students of color. For example, they must monitor how students are assigned to formal mentors, provide training programs for faculty mentors, and make strong statements about the importance of diversity initiatives. Administrators must be sure that there are no institutional barriers that hinder academic success. This often involves support for retention activities to address the graduation rates for students of color, which generally lag far behind those of majority students.

Strong support of student organizations, including those that are focused around minority students, sends important messages and also provides opportunities for collaborative efforts. For example, some student organizations are involved in recruiting, retention, and peer mentorship programs, but often their home departments have little contact with them and provide little support. Additionally, academic administrators must be cognizant of mentoring inequities if junior minority faculty are asked to help all students of color or are expected both to mentor individuals and to serve as advisers to student organizations. These practices not only perpetuate a system with unfairness to the faculty of color (expectations not required of others) but they jeopardize tenure and promotion opportunities as well.

\section{Concluding Comments}

This chapter has attempted to bring together several perspectives on diversity and mentoring. In a society that stresses differences and uniqueness, undergraduates, regardless of race and ethnicity, are remarkably similar in their goals, aspirations, and desire to be successful. Yet students often see the world differently based on the experiences that they bring with them to their respective campuses. Diversity and multiculturalism are areas in which students often differ in their initial perceptions. Diversity also plays an important role on campus because students have different experiences throughout their four years. Often, though not necessarily always, student campus experiences are affected by race, ethnicity, and gender. Higher education is a 
microcosm of society at large, and many of the significant issues involving social justice, diversity, and merit are at work on the campus. At the same time, all students are struggling with transitions from high school to college and are entering unfamiliar environments with multiple identity concerns. It is often faculty that, through formal and informal mentoring, have the opportunity to assist students in navigating through the educational system.

Faculty are key players in the development of students. Diversity is a crucial social element of life in the twenty-first century, and campuses are the place where students have the opportunity to explore the future with their mentors. The prominent emphasis on multiculturalism and diversity has resulted in faculty having to examine their own previous assumptions and consider how they interact with the increasingly diverse populations of students. In the process, diversity itself provides opportunities for both students and faculty to learn and to have an impact on one another.

\section{References}

Astin, A. W. "Diversity and Multiculturalism: How Are Students Affected?" Change, 1993, 25(2), 44-49.

Pascarella, E., Terenzini, P, and Hibel, J. Journal of Higher Education, 1978, 49(5), 450-463.

Tinto, V. Leaving College: Rethinking the Causes and Cures of Student Attrition (2nd ed.). Chicago: University of Chicago Press, 1993.

University of Michigan, Office of Academic Multicultural Initiatives. The Michigan Student Study. Matlock, J. and Gurin, G. (principal investigators). Ann Arbor, Michigan, 1999.

MARGARET SCISNEY-MATLOCK is associate professor in the School of Nursing at the University of Michigan and also directs a faculty project exploring strategies for training faculty in multicultural learning and teaching techniques.

JOHN MATLOCK is assistant provost in the Office of the Provost, executive vice president for academic affairs, and director of the Office of Academic Multicultural Initiatives at the University of Michigan. He has done extensive research on the impact of institutional diversity initiatives on undergraduate students during their four years in college. 